\title{
Changes in Leaf Length, Width, Area, and Photosynthesis of Fruit Cucumber in a Greenhouse Production System
}

\author{
Xiaotao Ding \\ School of Agriculture and Biology, Shanghai Jiaotong University, Shanghai \\ 202400, China; and Shanghai Key Lab of Protected Horticultural \\ Technology, Shanghai Academy of Agricultural Sciences, Shanghai \\ 201106, China
}

\author{
Liyao Yu \\ School of Agriculture and Biology, Shanghai Jiaotong University, Shanghai \\ 202400, China
}

Yuping Jiang

Faculty of Ecological Technology and Engineering, Shanghai Institute of Technology, Shanghai 201418, China

Shaojun Yang, Lizhong He, and Qiang Zhou

Shanghai Key Lab of Protected Horticultural Technology, Shanghai Academy of Agricultural Sciences, Shanghai 201106, China

\section{Jizhu Yu}

Shanghai Key Lab of Protected Horticultural Technology, Shanghai Academy of Agricultural Sciences, Shanghai 201106, China

\section{Danfeng Huang \\ School of Agriculture and Biology, Shanghai Jiaotong University, Shanghai 202400, China}

Additional index words. cucumber, leaf morphology, leaf position, model building, photosynthetic variable

\begin{abstract}
Changes in leaf length, width, area, weight, chlorophyll and carotenoids contents, and photosynthetic variables with different leaf positions were investigated in fruit cucumber. Plants were grown on rockwool slabs in an environmentally controlled greenhouse and irrigated by drip fertigation. Leaf measurements were conducted from the first to the 15th leaf (the oldest to the youngest). The results showed that fresh weight per unit leaf area decreased from the second to the 15th leaf. Changes in cucumber leaf length, width, and area followed quadratic models from the first to the 15th leaf. The quadratic models of leaf length, width, and area fit the measurements well, with $R^{2}$ values of $0.925,0.951$, and 0.955 , respectively. The leaf chlorophyll $a$ and $b$ and carotenoid contents increased from the oldest leaf (first leaf) to the youngest leaf and decreased after reaching the highest values. Changes in the net photosynthetic rate $\left(P_{n}\right)$ also followed the quadratic model from the first to the 15th leaf, with $R^{2}$ values of 0.975 . The leaf transpiration rate $\left(T_{r}\right)$ increased from the first to the 14th leaf. Our results revealed patterns in leaf growth and photosynthetic changes at different leaf positions in fruit cucumber and improved our understanding of the growth and development of fruit cucumber in the greenhouse production system.
\end{abstract}

Cucumber (Cucumis sativus) is among the most widely grown vegetables in the world and is native to the Indian subcontinent (Sebastian et al., 2010). It spread eastward to China $\approx 2000$ years ago and westward to Europe 700 to 1500 years ago (Weng et al., 2015). Fruit cucumber is the fresh-eating type of cucumber that was recently introduced from Europe to China. Fruit cucumber is popular with consumers due to its crisp and tender taste and because it is convenient to eat.

A well-developed canopy with a high photosynthetic rate is the foundation of biomass accumulation and crop productivity.
Recently, a few growth models, using leaf number, photosynthetically active radiation or temperature as variables have been established to predict the canopy growth of greenhouse crops (Fan et al., 2015; Zúñiga, 2014). In previous studies, models of leaf area, leaf number, growing degree days, and dry matter distribution (Gijzen et al., 1998; Kahlen, 2006; Marcelis et al., 1992, 1998; Uzun, 2006) were developed. Xu et al. (2010) integrated some of those parameters and demonstrated the precise prediction of cucumber and pepper growth in a greenhouse (Xu et al., 2010). All of the crop model studies mainly focus on increasing productivity along with quality and enriching crop management practices.

In crop production systems, the maximum photosynthetic capacity is usually difficult to achieve because of physiological and environmental limitations, such as varied leaf maturity, light deficiency caused by leaf shade, cloudy weather, sunlight incidence angle, greenhouse structure shade, and other environmental conditions, especially for crops with large leaf areas, such as fruit cucumber, in greenhouse vertical culture (Gunnlaugsson and Adalsteinsson, 2006; Lu et al., 2012; Matsuda et al., 2014). Leaf area and other growth indices at different leaf positions have been studied in tomato by Chang et al. (2011) and in purple yam by Hgaza et al. (2009), but the leaf growth and photosynthetic characteristics of fruit cucumber at different positions remain unclear.

We performed a comprehensive and systematic study on the leaf growth and photosynthetic characteristics of cucumber leaves at different positions. The information generated in this study will provide a reliable theoretical and practical basis for fruit cucumber cultivation in glass greenhouses.

\section{Materials and Methods}

Experimental facility and materials. The experiment was conducted in a glass greenhouse at the Chongming base of the National Engineering Research Center of Protected Agriculture, Shanghai Academy of Agriculture Sciences, in Spring 2017. The utility systems of the greenhouse include groundwater sources (hot and cold water wells), groundwater energy exchange systems (high efficiency plate energy exchangers), heat pumps, end systems (greenhouse heating ducts and air treatment units), and energy storage systems (heat storage tanks and cold storage tanks). The operating modes of the

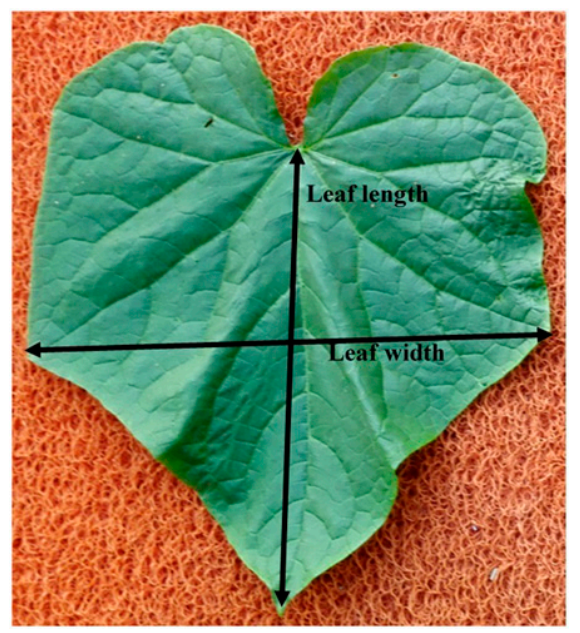

Fig. 1. Leaf length and width of cucumber plant, as used in the Cho et al. (2007) model. Leaf length was measured from the lamina tip to the intersection of the lamina and petiole along the lamina midrib. Leaf width was measured from tip to tip between the widest lamina lobes. 


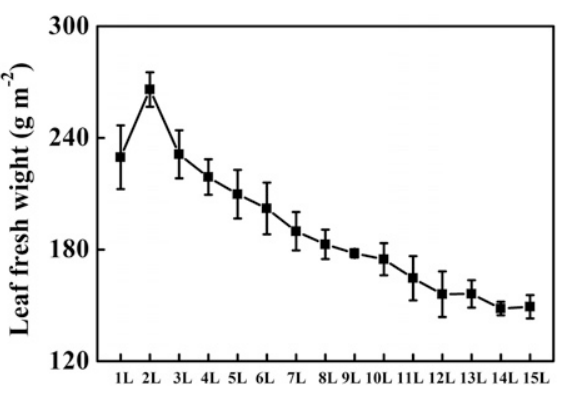

Fig. 2. Leaf fresh weight per unit leaf area at different positions. $1 \mathrm{~L}$ through $15 \mathrm{~L}$ indicate first through the 15 th leaves.

utility and climate control systems can be referenced in Ding et al. (2019). Normally, the vents were opened during the day when temperatures exceeded $24{ }^{\circ} \mathrm{C}$, and the heat system was turned on at night and maintained at $17{ }^{\circ} \mathrm{C}$. The air temperature, relative humidity $(\mathrm{RH})$, and $\mathrm{CO}_{2}$ concentration in the greenhouse were monitored and controlled automatically. Measurements were recorded automatically at 5-min intervals using a climate sensor (Priva, Netherlands) in the greenhouse.

Seeds of cucumber (Cucumis sativus L. cv. Deltastar) were sowed directly in watersoaked rockwool blocks $(10 \times 10 \times 6.5 \mathrm{~cm})$ and covered with vermiculite substrate. $\mathrm{Cu}$ cumber seedlings with uniform size and one fully unfolded leaf were transplanted onto rockwool slabs $(100 \times 20 \times 7.5 \mathrm{~cm})$ in the greenhouse and irrigated by drip fertigation. Plants were pruned to a single stem, and one flower was kept at each node from the sixth node onward. The stem density was 2.8 stems $/ \mathrm{m}^{2}$ and the plants grew using a highwire growing system.

The management of the irrigation nutrient solution depended on radiation accumulation, and the drain of nutrient solution was

Received for publication 15 Oct. 2019. Accepted for publication 27 Nov. 2019.

Published online 1 June 2020.

This work was supported by the Shanghai Agricultural Creation Character (2-3, 2019), Natural Science Foundation of Shanghai (18ZR1433200), Agricultural Basic Research of the Shanghai Agriculture Commission (7-2-1, 2014) and Promotion Project of Shanghai Agriculture Commission (4-5, 2018). The funders had no role in study design, data collection and analysis, decision to publish, or preparation of the manuscript. We thank Dr. Dafeng Hui for the technical editing of the manuscript.

X.D. and L.Y. contributed equally to this work.

J.Y., X.D., and D.H. conceived and designed the experiments. X.D., Y.J., S.Y., and L.H. performed the experiments. Y.J., X.D., and D.H. analyzed the data. X.D. and Q.Z. contributed reagents, materials, and analysis tools. X.D. and L.Y. wrote the paper.

J.Y. and D.H. are the corresponding authors. E-mail: 13636569665@163.com or hdf@situ.edu. cn.

This is an open access article distributed under the CC BY-NC-ND license (https://creativecommons. org/licenses/by-nc-nd/4.0/).
$20 \%$ to $30 \%$ of the applied solution every day. An electrical conductivity of 2.0 to 2.5 $\mathrm{dS} \cdot \mathrm{m}^{-1}$ and $\mathrm{pH}$ of 5.5 were maintained for the nutrient solution.

Experimental design. The experimental greenhouse was divided into three plots, and 700 plants were planted in each plot. When the plants had 15 leaves (1 month after transplantation), harvesting of cucumber was started. The plant height was $\approx 1.5 \mathrm{~m}$, and the first leaf at the bottom remained green at the time. At least three plants were selected in every plot at random and the length, width, and photosynthetic variables of all 15 leaves from bottom to top for each plant on sunny days were measured.

Leaf length, width, and area measurements. The length and width of 15 leaves from the bottom to the top were measured with a caliper, and the mean of every leaf length and width was calculated. Leaf length was measured from the lamina tip to the intersection of the lamina and petiole along the lamina midrib. Leaf width was measured from tip to tip between the widest lamina lobes, as referenced in Cho et al. (2007) (Fig. 1). The measurement of leaf area was carried out according to the method of Cho et al. (2007), in which the leaf area (SA) = $-210.61+13.358 *$ leaf width $+0.5356 *$ leaf length * leaf width.

Chlorophyll and carotenoid measurements. The methods of Lichtenthaler were adopted and optimized (Lichtenthaler and Wellburn, 1983), and leaf discs with particular diameters cut by hole punchers were soaked in $5 \mathrm{~mL}$ of acetone and ethanol, with a $2: 1$ ratio, until the leaves became completely white. The extraction solutions were measured with an ultraviolet-visible spectrophotometer (Shimadzu ultraviolet-2700; Japan) at wavelengths of 663,654 , and $470 \mathrm{~nm}$.

Leaf photosynthesis measurements. The net photosynthesis rate $\left(\mathrm{P}_{\mathrm{n}}\right)$, stomatal con- ductance $\left(g_{\mathrm{S}}\right)$, intercellular $\mathrm{CO}_{2}$ concentration $\left(\mathrm{C}_{\mathrm{i}}\right)$, and transpiration rate $\left(\mathrm{T}_{\mathrm{r}}\right)$ of all 15 leaves were measured with a LI-6400 Photosynthesis System (LI-COR Inc., Lincoln, $\mathrm{NE}$ ). The irradiance level was set at 1000 $\mu \mathrm{mol} \cdot \mathrm{m}^{-2} \cdot \mathrm{s}^{-1}$. Air temperature, $\mathrm{RH}$, and $\mathrm{CO}_{2}$ concentration were set at ambient conditions in the greenhouse (Jiang et al., 2017b).

Statistical analysis. Statistical analysis was conducted using SAS software (SAS version 9.3, SAS Institute Inc., Cary, NC). The results are presented as the mean \pm SD, with a minimum of three replicates. Figures were plotted using Origin 7.0 software (Origin Laboratory, Northampton, MA).

\section{Results}

Changes in leaf fresh weight per unit leaf area at different positions. At the stage of complete unfolding of the 15 th fruit cucumber leaf, the second leaf had the highest fresh weight per unit leaf area, and this value declined from the third to the upper leaves, and the 14th and 15th leaves had the lowest fresh weight (Fig. 2). There was no clear difference in fresh weight per unit leaf area between the first and third leaves (Fig. 2).

Changes in leaf chlorophyll and carotenoid contents at different positions. The chlorophyll $a$ and $b$, and total chlorophyll contents increased rapidly from the first to the third leaf, maintained the high levels from the third to the sixth leaf, declined gradually from the seventh to the 10th leaf, and decreased drastically from the 11 th to the 15 th leaf (Fig. 3). The leaf carotenoid content increased rapidly from the first to the third leaf, increased slowly from the third to the fifth leaf, declined gradually from the sixth to the 10th leaf, and decreased drastically from the 11 th to the 15 th leaf (Fig. 3).

Changes in leaflength, width, and area at different positions. The leaf length, width,

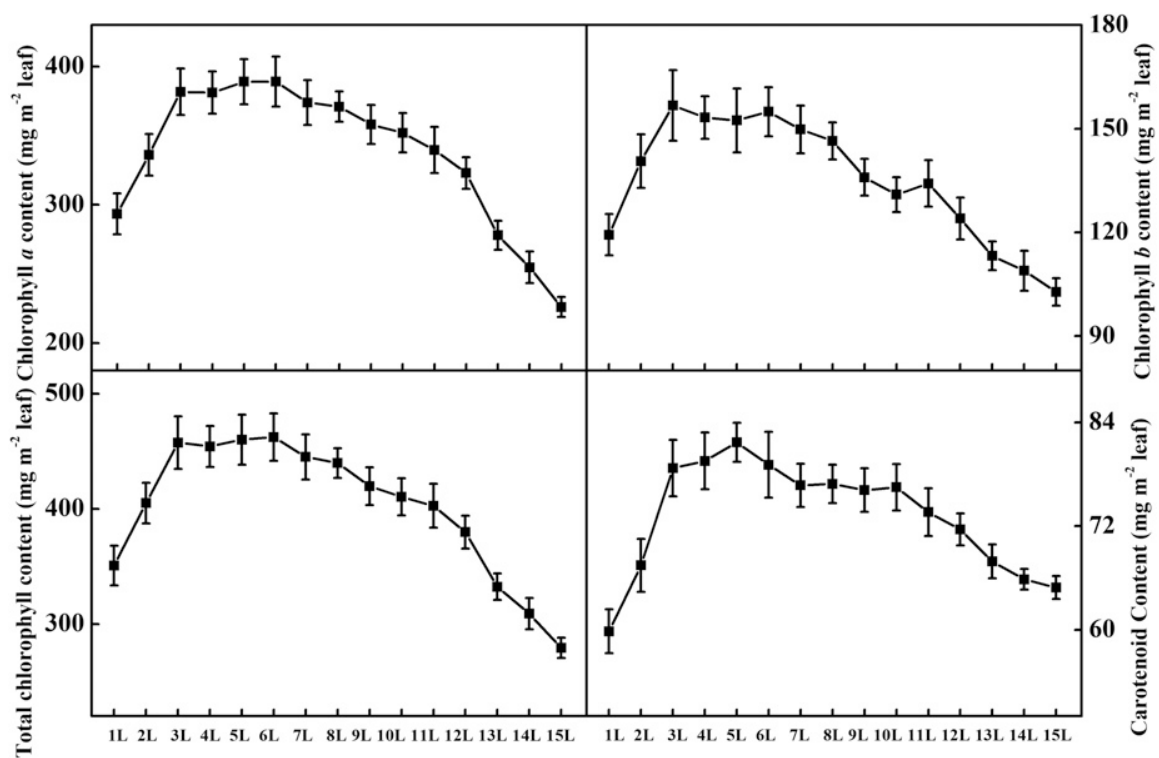

Fig. 3. Leaf chlorophyll $a$ and $b$, total chlorophyll, and carotenoid content at different positions. 1L through $15 \mathrm{~L}$ indicate first through the 15 th leaves. 


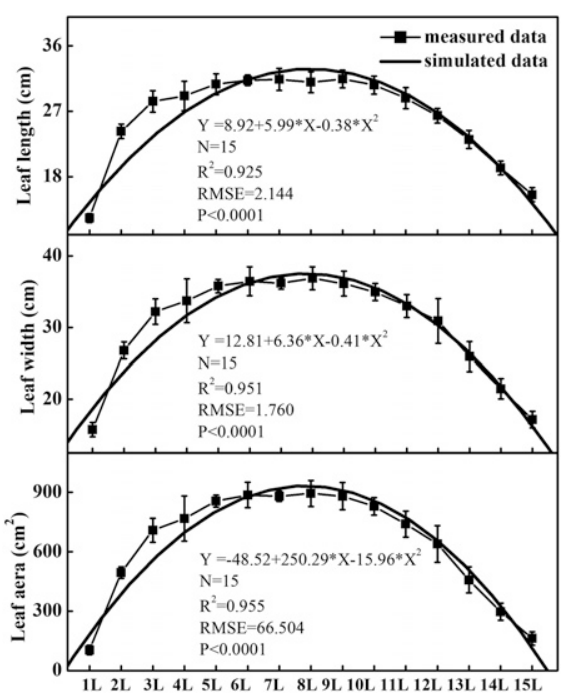

Fig. 4. Leaf length, width and area of cucumber at different positions. $1 \mathrm{~L}$ through $15 \mathrm{~L}$ indicate first through the 15th leaves. RMSEA $=$ root mean square error of approximation.

and area increased rapidly from the first to the third leaf, increased slowly from the fourth to the eighth leaf, and declined gradually from the ninth to the 15th leaf (Fig. 4). The relationship of leaf length, width, area and leaf position showed a quadratic equation, and the $R^{2}$ determination coefficient values were $0.925,0.951$, and 0.955 , respectively $(P<0.0001)$. The exponential model fit the measurements well. There was a large discrepancy between the measured values and the simulated values of the lower eight leaves, whereas one discrepancy of the upper seven leaves was small, indicating that the simulated values were close to the measured values from the ninth to the 15 th leaf (Fig. 4).

Changes in leaf gas exchange parameters at different positions. The $\mathrm{P}_{\mathrm{n}}$ of the leaves increased gradually from the first to the seventh leaf under saturated light, remained steady from the seventh to the 10th leaf, with values all $>21 \mu \mathrm{mol} \cdot \mathrm{m}^{-2} \cdot \mathrm{s}^{-1} \mathrm{CO}_{2}$, and declined from the 11 th to the 15 th leaf. The change in $\mathrm{P}_{\mathrm{n}}$ among different positions fit the quadratic model well with an $R^{2}$ of $0.975(P<0.0001)$ (Fig. 5; Table 1). The $g_{\mathrm{S}}$ increased from the first to the 12th leaf and decreased gradually from the 12 th to the 15 th leaf. The $\mathrm{T}_{\mathrm{r}}$ increased from the first to the 14th leaf and decreased in the 15th leaf (Fig. 5).

Comparison between simulated and measured values of leaf length, width, area, and $P_{n}$ at different positions. The $R^{2}$ deter- mination coefficient values of leaf length, width, area, and $\mathrm{P}_{\mathrm{n}}$ of leaves at different position based on a 1:1 straight line between the simulated values and measured values were $0.900,0.943,0.946$, and 0.973 , respectively (Fig. 6), which means that the models fit well. $P_{n}$ had the smallest discrepancy between the simulated values and measured values, whereas that of leaf length was the largest.

\section{Discussion}

According to the results for unit fresh weight per leaf area, the second leaf from the bottom had the largest unit fresh weight per leaf area at the 15-leaf stage, and the values declined from the third to the 15th leaf. This might be related to the accumulation of photosynthetic products in different leaves, which mainly depends on the internal growth characteristics of fruit cucumber (Hikosaka, 2005; Poorter et al., 2009).

Leaf chlorophyll and carotenoids are vital components of the plant photosynthetic system and play significant roles in light energy capture, maintenance of the stability of the thylakoid membrane, and energy transduction (Tanaka and Tanaka, 2006). We found that the overall variation in chlorophyll

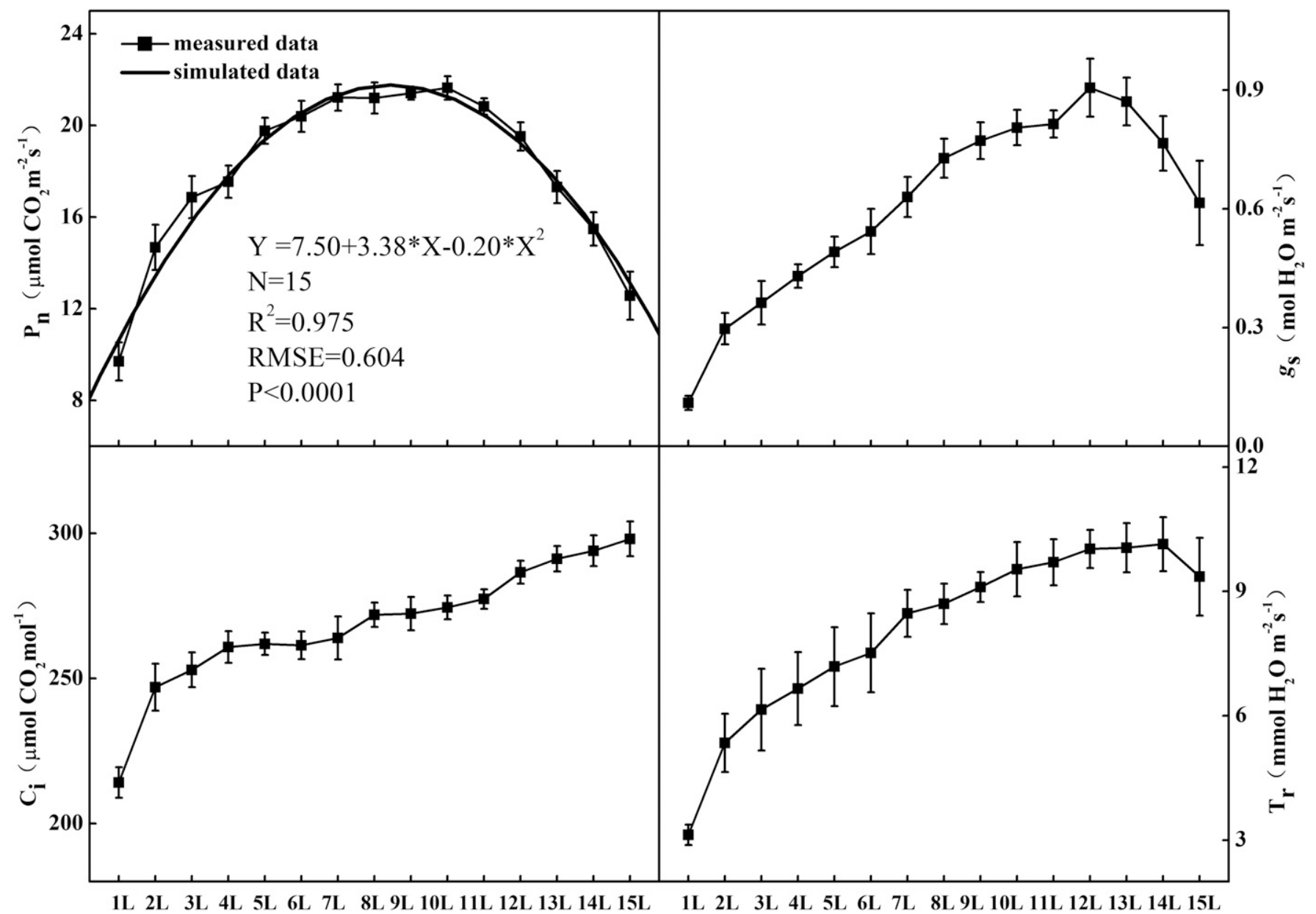

Fig. 5. Leaf photosynthetic variables at different positions. $1 \mathrm{~L}$ through $15 \mathrm{~L}$ indicate first through the 15 th leaves. RMSEA $=$ root mean square error of approximation; $\mathrm{P}_{\mathrm{n}}=$ net photosynthetic rate; $\mathrm{C}_{\mathrm{i}}=$ intercellular $\mathrm{CO}_{2}$ concentration; $g_{\mathrm{S}}=$ stomatal conductance; $\mathrm{T}_{\mathrm{r}}=$ leaf transpiration rate. 
Table 1. Regression models of leaf length, width, area, and $\mathrm{P}_{\mathrm{n}}$ with leaf position.

\begin{tabular}{lllrr}
\hline & \multicolumn{1}{c}{ Equation } & $\mathrm{N}$ & $R^{2}$ & $\mathrm{RMSE}$ \\
\hline Leaf length & $\mathrm{Y}=8.92+5.99 * \mathrm{X}-0.38^{*} \mathrm{X}^{2}$ & 15 & 0.925 & 2.144 \\
Leaf width & $\mathrm{Y}=12.81+6.36 * \mathrm{X}-0.41 * \mathrm{X}^{2}$ & 15 & 0.951 & 1.760 \\
Leaf area & $\mathrm{Y}=-48.52+250.29 * \mathrm{X}-15.96 * \mathrm{X}^{2}$ & 15 & 0.955 & $<0.0001$ \\
$\mathrm{P}_{\mathrm{n}}$ & $\mathrm{Y}=7.50+3.38 * \mathrm{X}-0.20 * \mathrm{X}^{2}$ & 15 & 0.975 & $<004$ \\
\hline
\end{tabular}

RMSEA $=$ root mean square error of approximation; $\mathrm{P}_{\mathrm{n}}=$ net photosynthetic rate.
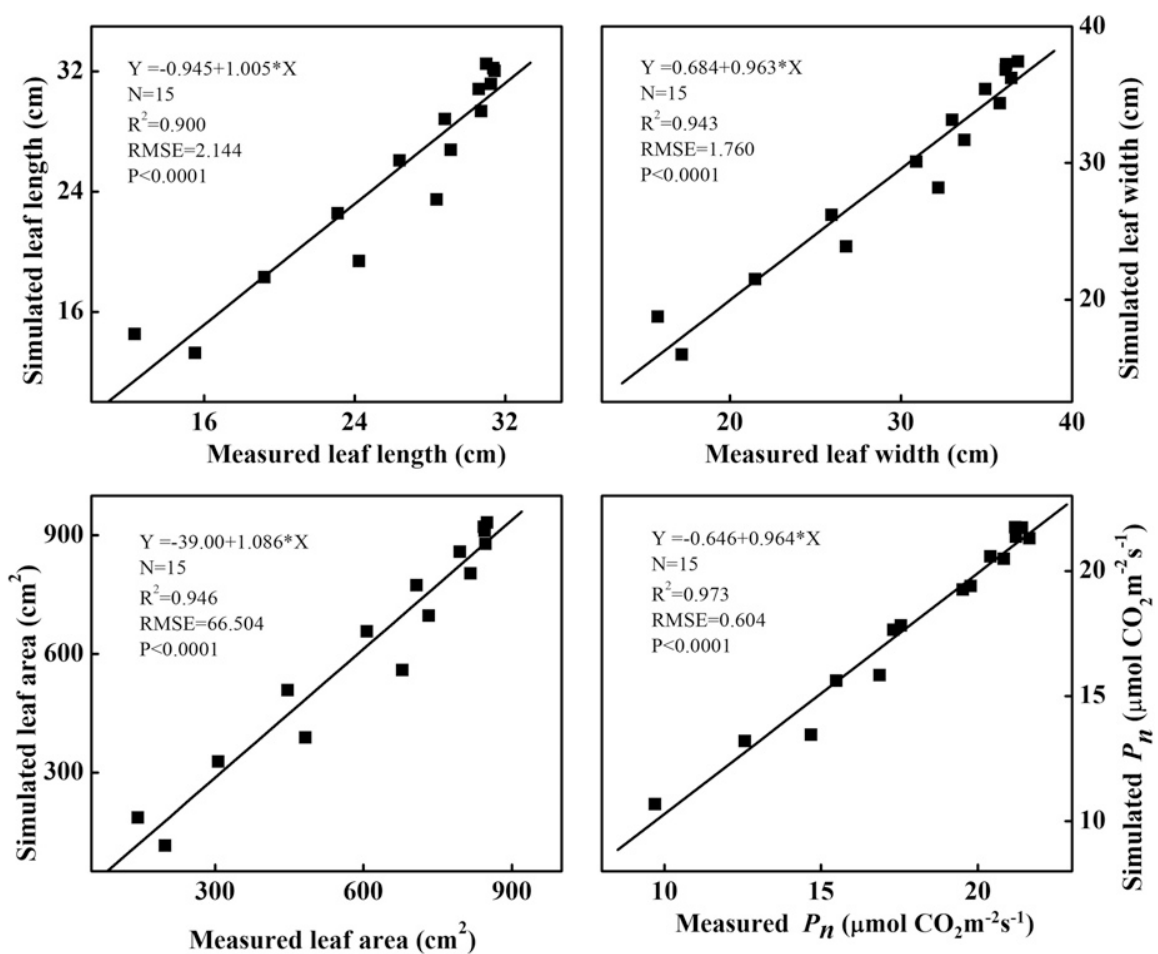

Fig. 6. Comparison between simulated and measured values of leaf length, width, area, and net photosynthetic rate at different positions. RMSEA = root mean square error of approximation.

$a$, chlorophyll $b$, and carotenoid shared similar patterns from the first to the 15th leaf, meaning that the middle leaves possessed higher contents, and the bottom and upper leaves had lower contents. The most likely reason for this finding was that the bottom leaves had senesced, and the top leaves were not yet mature at this time (Hovi et al., 2004; Zou et al., 2011). A similar result was shown in research on the effects of interlighting on cucumber growth, which showed that the chlorophyll content and light absorptance reached maximum values in the seventh to eighth leaves in a greenhouse cucumber canopy (Trouwborst et al., 2010).

The results show that there were quadratic relationships between changes in leaf length, width, area, and position from the first to the 15 th leaf. The $R^{2}$ values were all $>0.9$, which indicates that these equations could accurately predict the changes at different positions. Basically, the maximal leaf length, width, and area were recorded at approximately the fifth through 10th leaf from the bottom. This result was partially consistent with the research of Xu et al. (2010), in which the leaf growth change was asymmetric between two sides of approximately the 10th leaf, where the maximum leaf area occurred.
Leaf growth increases rapidly before that point and declines slowly from the 10th to the 40th leaf (Xu et al., 2010). One possible reason to explain this difference may be the duration of cultivation. With long-term cultivation, the cucumber plants have enough time to extend most of their middle leaves. The leaf area index (LAI), the total leaf area per unit land area, is a key parameter in the analysis of plant photosynthesis, transpiration, water use, and productivity. In this study, the LAI of fruit cucumber (from the first to the 15 th leaf) was $\approx 2.69$. Although previous studies have shown that in a winter greenhouse environment, a canopy LAI of 2 to 3 is optimal for cucumber production, an experiment in summer indicated that LAI of 3 to 4 provides the highest gross photosynthesis (Luo et al., 2005a, 2005b). Therefore, the proper LAI of fruit cucumber may be obtained when the 20th leaf begins to unfold in spring experiments, which requires further study according to the crop characteristics, growing season, and cultivation management (Xu et al., 2010).

Photosynthesis is the primary component of productivity that provides energy and assimilates for growth and reproduction in plants (Lawlor, 2009). The $\mathrm{P}_{\mathrm{n}}$ of fruit cucum- ber followed the quadratic model from the first to the 15th leaf, and the change in $P_{n}$ of leaves at different positions can be predicted well by this equation. Trouwborst et al. (2011) measured the photosynthesis of leaves at different layers and revealed similar results. The $P_{n}$ of both bottom and top leaves was remarkably lower than that of middle leaves, which could be related to senescence (Ashraf and Harris, 2013) and lack of light (Wolff and Langerud, 2006) of bottom leaves and immaturity of top leaves (Cho et al., 2007). The results of our research showed that light conditions and $\mathrm{C}_{\mathrm{i}}$ improved from the bottom to the top leaves, but $g_{\mathrm{S}}$ declined from the 13 th to the 15 th leaf, which indicated that the main reason for the $\mathrm{P}_{\mathrm{n}}$ reduction of bottom leaves was stomatal limitation and that nonstomatal limitation accounted for the $P_{n}$ reduction of top leaves. This result was supported by research by Pettersen et al. (2010), in which a low $g_{S}$, light compensation point and respiration rate were observed in the lower canopy. Ding et al. (2013) reported that weak light resulted in a remarkable decrease in the cucumber net $P_{n}$. Gunnlaugsson and Adalsteinsson (2006) found that lower leaves can also achieve a high accumulation rate under horizontal artificial light. This may indicate that the light deficiency of lower leaves accounts mostly for the observed low $\mathrm{P}_{\mathrm{n}}$. In actual cultivation, shading within plants or leaves is inevitable. Previous research has shown that shading of lower leaves not only weakens the real-time $\mathrm{P}_{\mathrm{n}}$ and assimilation rate directly but also results in leaf damage, which in turn leads to additional photosynthetic decline ( $\mathrm{Lu}$ et al., 2012; Steinger et al., 2003). Some studies in tomato culture were performed to adjust plant density dynamically among various growth periods (Jiang et al., 2017a), and this may also provide a feasible solution in cucumber production.

In conclusion, variations in leaf length, width, area, and $\mathrm{P}_{\mathrm{n}}$ of fruit cucumber precisely followed the quadratic model, and the model fit very well with the measured value changes. The bottom leaf still had high $P_{n}$ at the 15-leaf stage, so the time to remove aged leaves should be later, such as the 20-leaf stage, so that 18 leaves are maintained for plant photosynthesis (Ding et al., 2019). The middle leaves had the highest $\mathrm{P}_{\mathrm{n}}$, and the reasons for the decline in $\mathrm{P}_{\mathrm{n}}$ of bottom leaves and upper leaves were stomatal limitations and nonstomatal limitations, respectively. The pattern of variation in the leaf photosynthetic variables at different positions improves our understanding of leaf properties and growth and provides guidance for proper cultivation of cucumber in the greenhouse. 


\section{Literature Cited}

Ashraf, M. and P.J.C. Harris. 2013. Photosynthesis under stressful environments: An overview. Photosynthetica 51:163-190.

Chang, L.Y., S.P. He, M.H. Chi, and D.F. Huang. 2011. Temperature-driven growth shape simulation and model of greenhouse melon leaves. Math. Comput. Model. 54(3):1175-1180.

Cho, Y.Y., S.B. Oh, M.M. Oh, and J.E. Son. 2007. Estimation of individual leaf area, fresh weight, and dry weight of hydroponically grown cucumbers (Cucumis sativus L.) using leaf length, width, and SPAD value. Scientia Hort. 111:330-334.

Ding, X.T., Y.P. Jiang, D.F. Hui, L.Z. He, D.F Huang, J.Z. Yu, and Q. Zhou. 2019. Model simulation of cucumber yield and microclimate analysis in a semi-closed greenhouse in China. HortScience 54:1-8.

Ding, X.T., Y.P. Jiang, H. Wang, H.J. Jin, H.M Zhang, C.H. Chen, and J.Z. Yu. 2013. Effects of cytokinin on photosynthetic gas exchange, chlorophyll fluorescence parameters, antioxidative system and carbohydrate accumulation in cucumber (Cucumis sativus L.) under low light. Acta Physiol. Plant. 35:1427-1438.

Fan, X.R., M.Z. Kang, E. Heuvelink, P. de Reffye, and B.G. Hu. 2015. A knowledge-and-datadriven modeling approach for simulating plant growth: A case study on tomato growth. Ecol. Model. 312:363-373.

Gijzen, H., E. Heuvelink, and H. Challa. 1998. Hortisim: A model for greenhouse crops and greenhouse climate. Acta Hort. 456:441-450.

Gunnlaugsson, B. and S. Adalsteinsson. 2006. Interlight and plant density in year-round production of tomato at northern latitudes. Acta Hort. 711:71-76.

Hgaza, V.K., L.N. Diby, S. Aké, and E. Frossard. 2009. Leaf growth and photosynthetic capacity as affected by leaf position, plant nutritional status and growth stage in Dioscorea alata L. J. Anim. Plant Sci. 5(2):483-493.

Hikosaka, K. 2005. Leaf canopy as a dynamic system: Ecophysiology and optimality in leaf turnover. Ann. Bot. 95:521-533.

Hovi, T., J. Näkkilä, and R. Tahvonen. 2004 Interlighting improves production of yearround cucumber. Scientia Hort. 102:283-294.

Jiang, C., M. Johkan, M. Hohjo, S. Tsukagoshi, M. Ebihara, A. Nakaminami, and T. Maruo. 2017a. Responses of leaf photosynthesis, plant growth and fruit production to periodic alteration of plant density in winter produced single-truss tomatoes. Hort. J. 86:511-518.

Jiang, Y.P., X.T. Ding, D. Zhang, Q. Deng, C.L. Yu, S.P. Zhou, and D.F. Hui. 2017b. Soil salinity increases the tolerance of excessive sulfur fumigation stress in tomato plants. Environ. Exp. Bot. 133:70-77.

Kahlen, K. 2006. 3D architectural modelling of greenhouse cucumber (Cucumis sativus L.) using L-systems. Acta Hort. 718:51-58.

Lawlor, D.W. 2009. Musings about the effects of environment on photosynthesis. Ann. Bot. 103:543-549.

Lichtenthaler, H.K. and A.R. Wellburn. 1983. Determination of total carotenoids and chlorophylls $\mathrm{a}$ and $\mathrm{b}$ of leaf in different solvents. Biochem. Soc. Trans. 11:591-592.

Lu, N., T. Maruo, M. Johkan, M. Hohjo, S. Tsukagoshi, Y. Ito, T. Ichimura, and Y. Shinohara. 2012. Effects of supplemental lighting within the canopy at different developing stages on tomato yield and quality of singletruss tomato plants grown at high density. Environ. Control Biol. 50:1-11.

Luo, W., H.F.D. Zwart, J.F. Dai, X.H. Wang, C. Stanghellini, and C.X. Bu. 2005a. Simulation of greenhouse management in the subtropics I. Model validation and scenario study for the winter season. Biosyst. Eng. 90:307-318.

Luo, W., C. Stanghellini, J.F. Dai, X.H. Wang, H.F.D. Zwart, and C.X. Bu. 2005b. Simulation of greenhouse management in the subtropics II. Scenario study for the summer season. Biosyst. Eng. 90:433-441.

Marcelis, L.F.M. 1992. The dynamics of growth and dry matter distribution in cucumber. Ann. Bot. 69:487-492.

Marcelis, L.F.M., E. Heuvelink, and J. Goudriaan. 1998. Modelling biomass production and yield of horticultural crops: A review. Scientia Hort. 74:83-111.

Matsuda, R., N. Ozawa, and K. Fujiwara. 2014. Leaf photosynthesis, plant growth, and carbohydrate accumulation of tomato under differen photoperiods and diurnal temperature differences. Scientia Hort. 170:150-158.

Pettersen, R.I., S. Torre, and H.R. Gislerød. 2010. Effects of intracanopy lighting on photosynthetic characteristics in cucumber. Scientia Hort. 125:77-81.

Poorter, H., Ü. Niinemets, L. Poorter, I.J. Wright, and R. Villar. 2009. Causes and consequences of variation in leaf mass per area (LMA): A meta-analysis. New Phytol. 182:565-588.

Sebastian, P.M., H. Schaefer, I.R.H. Telford, and S.S. Renner. 2010. Cucumber and melon have their wild progenitors in India, and the sister species of Cucumis melo is from Australia. Proc. Natl. Acad. Sci. USA 107:14269-14273.

Steinger, T., B.A. Roy, and M.L. Stanton. 2003. Evolution in stressful environments II: Adaptive value and costs of plasticity in response to low light in Sinapis arvensis. J. Evol. Biol. 16:313-323.

Tanaka, A. and R. Tanaka. 2006. Chlorophyll metabolism. Curr. Opin. Plant Biol. 9:248-255.

Trouwborst, G., J. Oosterkamp, S.W. Hogewoning, J. Harbinson, and W.V. Ieperen. 2010. The responses of light interception, photosynthesis and fruit yield of cucumber to LED-lighting within the canopy. Physiol. Plant. 138:289300 .

Trouwborst, G., H.C.M. Schapendonk, K. Rappoldt, S. Pot, S.W. Hogewoning, and W. Ieperen. 2011. The effect of intracanopy lighting on cucumber fruit yield-Model analysis. Scientia Hort. 129: 273-278.

Uzun, S. 2006. The quantitative effects of temperature and light on the number of leaves preceding the first fruiting inflorescence on the stem of tomato (Lycopersicon esculentum, Mill.) and aubergine (Solanum melongena L.). Scientia Hort. 109:142-146.

Weng, Y.Q., M. Colle, Y.H. Wang, L.M. Yang, M. Rubinstein, A. Sherman, R. Ophir, and R. Grumet. 2015. QTL mapping in multiple populations and development stages reveals dynamic quantitative trait loci for fruit size in cucumbers of different market classes. Theor Appl. Genet. 128:1747-1763.

Wolff, S.A. and A. Langerud. 2006. Fruit yield, starch content and leaf chlorosis in cucumber exposed to continuous lighting. Eur. J. Hort. Sci. 71:259-261.

Xu, R., J. Dai, W. Luo, X. Yin, Y. Li, X. Tai, L. Han, Y. Chen, L. Lin, G. Li, C. Zou, W. Du, and M. Diao. 2010. A photothermal model of leaf area index for greenhouse crops. Agr. For. Meteorol. 150:541-552.

Zou, X.B., J.Y. Shi, L.M. Hao, J.W. Zhao, H.P. Mao, Z.W. Chen, Y.X. Li, and H. Mei. 2011. In vivo noninvasive detection of chlorophyll distribution in cucumber (Cucumis sativus) leaves by indices based on hyperspectral imaging. Anal. Chim. Acta 706:105-112.

Zúñiga, E.C.T., I.L. López Cruz, and A.R. García. 2014. Parameter estimation for crop growth model using evolutionary and bioinspired algorithms. Appl. Soft Comput. 23:474-482. 